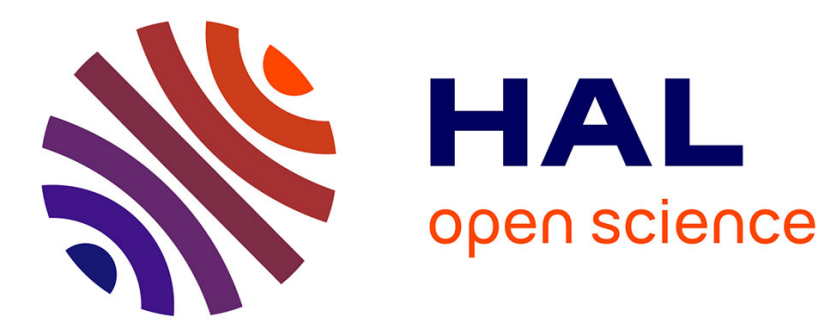

\title{
Switchable Polymerization Triggered by Fast and Quantitative Insertion of Carbon Monoxide into Cobalt-Oxygen Bonds
}

Yong Wang, Yajun Zhao, Shuaishuai Zhu, Xingping Zhou, Jing Xu, Xiaolin Xie, Rinaldo Poli

\section{To cite this version:}

Yong Wang, Yajun Zhao, Shuaishuai Zhu, Xingping Zhou, Jing Xu, et al.. Switchable Polymerization Triggered by Fast and Quantitative Insertion of Carbon Monoxide into Cobalt-Oxygen Bonds. Angewandte Chemie International Edition, 2020, 59 (15), pp.5988-5994. 10.1002/anie.201914216. hal-02565036

\section{HAL Id: hal-02565036 \\ https://hal.science/hal-02565036}

Submitted on 1 Mar 2021

HAL is a multi-disciplinary open access archive for the deposit and dissemination of scientific research documents, whether they are published or not. The documents may come from teaching and research institutions in France or abroad, or from public or private research centers.
L'archive ouverte pluridisciplinaire HAL, est destinée au dépôt et à la diffusion de documents scientifiques de niveau recherche, publiés ou non, émanant des établissements d'enseignement et de recherche français ou étrangers, des laboratoires publics ou privés. 


\title{
Switchable Polymerization Triggered by Fast and Quantitative Insertion of Carbon Monoxide into Cobalt-Oxygen Bonds
}

\author{
Yong Wang, ${ }^{\text {[a] }}$ Yajun Zhao, ${ }^{[a]}$ Shuaishuai Zhu, ${ }^{[a]}$ Xingping Zhou, ${ }^{[a]}$ Jing Xu, ${ }^{[b]}$ Xiaolin Xie ${ }^{[a]}$ and Rinaldo \\ Poli*[c]
}

\begin{abstract}
A strategy that uses carbon monoxide (CO) as a molecular trigger to switch the polymerization mechanism of a cobalt Salen complex $\left[\right.$ Salen $=(\mathrm{R}, \mathrm{R})-\mathrm{N}, \mathrm{N}^{\prime}$-bis (3,5-di-tertbutylsalicylidene)-1,2cyclohexanediamine] from ring-opening copolymerization (ROCOP) of epoxides/anhydrides to organometallic mediated controlled radical polymerization (OMRP) of acrylates is described. The key phenomenon is a rapid and quantitative insertion of $\mathrm{CO}$ into the $\mathrm{Co}-\mathrm{O}$ bond, allowing for in situ transformation of the ROCOP active species

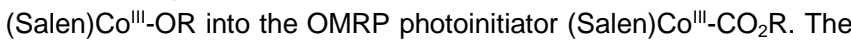
proposed mechanism, which involves $\mathrm{CO}$ coordination to (Salen)Co'I'$\mathrm{OR}$ and subsequent intramolecular rearrangement via migratory insertion has been rationalized by DFT calculations. Regulated by both $\mathrm{CO}$ and visible light, on-demand sequence control can be achieved for the one-pot synthesis of polyester- $b$-polyacrylate diblock copolymers $(\Theta<1.15)$.
\end{abstract}

\section{Introduction}

The fundamental properties and functionalities of polymers are directly correlated to their primary microstructures. Whereas enzymes display exceptional efficiency for the synthesis of precisely programmed biopolymers within a living cell, it is a major challenge to regulate polymer sequence and architecture from mixture of monomers for modern polymer chemistry. ${ }^{1}$ An attractive solution may lay in the rapidly evolving field of switchable catalysis, whereby the reactivity of a metal-based polymerization catalyst is altered in response to an external stimulus. $^{2}$ Typically, the switch involves a change of the active species, which is achieved either via in situ modification of the metal coordination sphere through a stimulus-responsive functional group, ${ }^{3}$ or by a metal oxidation state change via a redox process $^{4}$. In this regard, current achievements in switchable polymerization have mostly been limited to catalysts that iterate between mechanistically similar polymerization reactions.

[a] Dr. Y. Wang,Y. J. Zhao, S. S. Zhu, Prof. Dr. X. P. Zhou, Prof. Dr. X. L. Xie.

School of Chemistry and Chemical Engineering

Huazhong University of Science and Technology

Wuhan 430074, P. R. China

E-mail: tcwy@mail.hust.edu.cn; xpzhou@mail.hust.edu.cn

[b] Prof. Dr. J. Xu.

College of Chemistry and Material Science

Shandong Agricultural University

Taian 271018, P. R. China

[c] Prof. Dr. R. Poli.

Laboratoire de Chimie de Coordination (LCC-CNRS)

Université de Toulouse, UPS, INPT

205, route de Narbonne, 31077 Toulouse (France)

E-mail: rinaldo.poli@lcc-toulouse.fr

Supporting information for this article is given via a link at the end of the document.
The ring-opening copolymerization (ROCOP) of epoxides/anhydrides has emerged as a burgeoning method to produce polyesters. ${ }^{5}$ The wide availability of renewable monomers and the opportunity for post-polymerization modification open access to a myriad of new materials with unique properties that are not accessible through traditional condensation reactions. ${ }^{6}$ Cobalt Salcy [bis(salicylaldimine)] complexes featuring nucleophilic axial groups [(Salcy)Co'I"X; $\mathrm{X}=$ halides, carboxyl, etc.] are among the most investigated catalysts for the copolymerization, wherein the alternative insertion of anhydrides and epoxides is directly correlated to the reversible formation and dissociation of the Co-O bonds (Scheme $1 \mathrm{~A}){ }^{7}$ Relative to the polar $\mathrm{Co}-\mathrm{O}$ bonds, $\mathrm{Co}-\mathrm{C}$ bonds tend to break homolytically to generate carbon-based radicals as is known to occur, for instance, in the biological action of vitamin B12. ${ }^{8}$ This process may be promoted by thermal treatment or by light irradiation. ${ }^{9}$ Recently, cobalt complexes have been used to ensure the well-controlled polymerization of a wide variety of the challenging nonconjugated monomers through the strategy known as organometallic mediated controlled radical polymerization (OMRP) (Scheme 1B). ${ }^{10}$ Especially, Fu and Peng et al. demonstrated that an alkoxycarbonyl cobalt Salen complex (Salen is a specific Salcyl ligand with a trans-cyclohex-diyl tether, Scheme 2) could serve as the photoinitiator as well as the mediator for visible light controlled OMRP. ${ }^{11}$

In order to expand the application scopes of biodegradable polymers resulted from ROCOP, intensive research efforts have been directed to the rational design and synthesis of block copolymers by combining ROCOP and other living/controlled polymerization techniques. ${ }^{12}$ We have reported the one-step synthesis of well-defined $\mathrm{CO}_{2}$-based block copolymers via concurrent ROCOP and RAFT polymerization using a bifunctional chain transfer agent in 2018, however, only conjugated monomers such as methyl methacrylate (MMA) and styrene (St) were involved. ${ }^{12 b}$ In a recent contribution, we have illustrated a mechanistic switch involving ROCOP and OMRP with a (Salen)Co system as catalyst/mediator for both mechanisms. The switch operated in the OMRP-to-ROCOP direction via a $\mathrm{O}_{2-}$ triggered modification of the polymer chain end from Co-R to CoOR and was implemented for the development of diblock copolymers with a poly(vinyl acetate) block and a polycarbonate block (by ROCOP of $\mathrm{CO}_{2}$ /epoxides). ${ }^{2 \mathrm{~d}}$ Herein, we report a switch of polymerization mechanism in the opposite direction, from ROCOP of epoxides/anhydrides to OMRP, using carbon monoxide (CO) as a molecular trigger and the (Salen) $\mathrm{Co}^{\mathrm{II}} \mathrm{Cl}$ complex as the mediator (Scheme 2). Central to this protocol is the direct and quantitative insertion of $\mathrm{CO}$ into $\mathrm{Co}-\mathrm{O}$ bonds, which enables an in situ transformation of the ROCOP active species

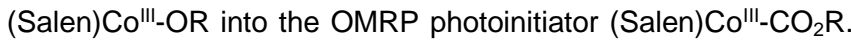
Although $\mathrm{CO}$ insertions into metal-carbon single and multiple bonds are implicated in many stoichiometric and catalytic transformations of great significance in both industrial and acade- 


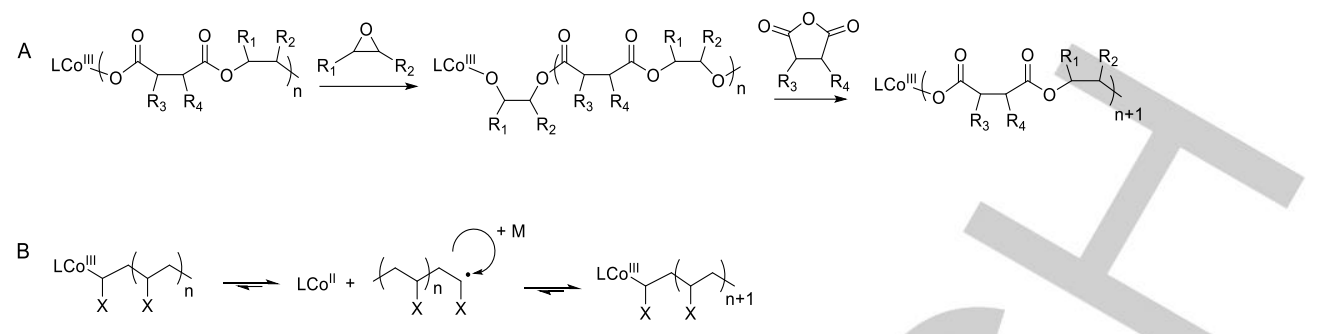

Scheme 1. Scheme 1 Chain propagation processes: cobalt(III) complex mediated ROCOP of anhydrides/epoxides (A); cobalt complex mediated controlled/ living radical polymerization of vinyl monomers $(B)$.

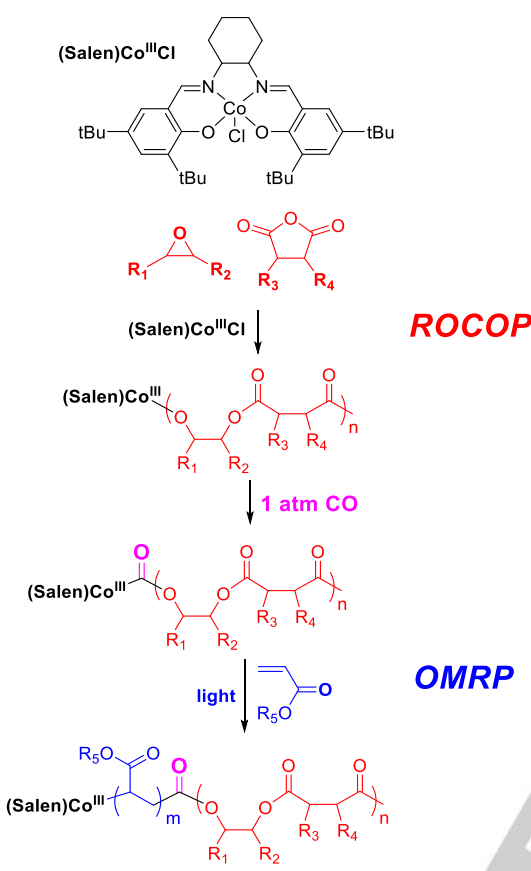

Scheme 2. CO-triggered switch from cobalt mediated ROCOP to OMRP for the one-pot synthesis of polyester- $b$-polyacrylate.

mic fields, ${ }^{13}$ those into a metal-oxygen bond are less common. ${ }^{14}$ Most are related to the Group 10 metals and all concern metals in oxidation states up to II. In those systems, the metal-alkoxide bonds are weakened by filled-filled orbital interactions between the $O$ lone pairs and the metal $d$ orbitals. This process is unprecedented, to the best of our knowledge, for cobalt and for a metal complex in an oxidation state as high as III.

\section{Results and Discussion}

CO-insertion study. In our primary effort to accomplish a switch from ROCOP to OMRP, we turned for inspiration to the work of Oertling and Kadish, which described the formation of $\left[(\text { Porphyrin }) \mathrm{Co}^{\text {III }}(\mathrm{CO})\right]^{+}$via binding of $\mathrm{CO}$ with [(Porphyrin)Co $]^{+}$at room temperature. ${ }^{15}$ The weak metal $\mathrm{d} \pi \rightarrow$ ligand $\pi^{*}$ backbonding

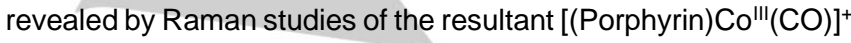
suggests that $\mathrm{CO}$ is largely $\sigma$-bonded to the metal and that the carbonyl carbon atom is quite positive charged. ${ }^{16}$ Under the assumption of a facile dissociation of (Salen)Co ${ }^{\text {III-OR into }}$ $\left[\left(\text { Salen)Co }{ }^{\prime \prime \prime}\right]^{+}\right.$and the highly nucleophilic -OR (Scheme 3A1), ${ }^{17}$ it

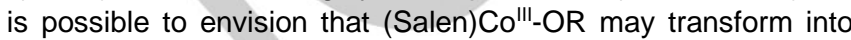

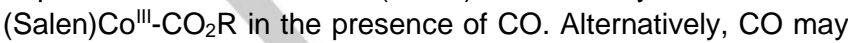
directly coordinate to (Salen)Co'll-OR and the resulting [(Salen)Co"'(CO)]OR adduct may intramolecularly rearrange via insertion (Scheme 3A2). Yet another possibility is ionic dissociation after $\mathrm{CO}$ coordination (Scheme $3 \mathrm{~A} 3$ ). All these mechanisms were previously shown to occur for other systems, depending on the nature of the complex and on the conditions. ${ }^{18}$ It is worth mentioning that the methoxycarbonyl cobalt complex (Salen)Co ${ }^{\text {III }-} \mathrm{CO}_{2} \mathrm{Me}$ used by $\mathrm{Fu}$ and Peng was synthesized by sequential oxidation of (Salen)Co" with oxone in methanol and carbonylation process with $\mathrm{CO}$, which is indicative of the

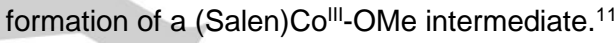
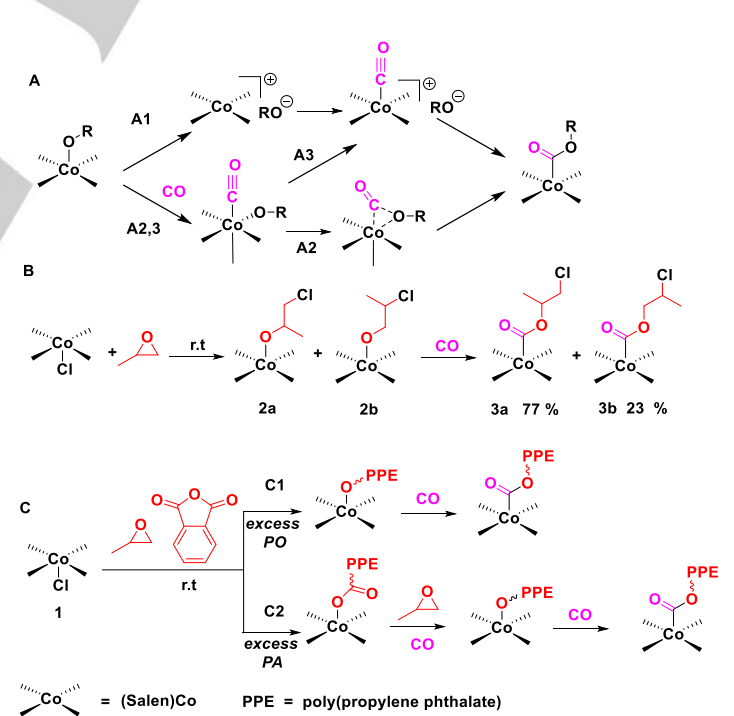

Scheme 3. Mechanistic aspects concerning the $\mathrm{CO}$ insertion into $\mathrm{Co}-\mathrm{O}$ bonds to form alkyloxy cobalt Salen complexes.

To verify this assumption, the stoichiometric ring-opening of

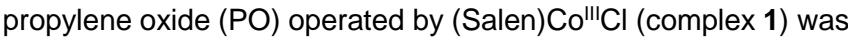
carried out in ampule at room temperature, aiming to obtain the moisture sensitive (Salen)Co-alkoxo intermediates (2a and $\mathbf{2 b}$ ) (Scheme 3B)..$^{19}$ The reaction mixture was then allowed to stir in the dark under $1 \mathrm{~atm} \mathrm{CO}$ for $12 \mathrm{~h}$ before removing the excess $\mathrm{PO}$ by evaporation under vacuum. The electrospray ionization mass spectrum (ESI-MS) of the resultant dark green powder displayed only one series of signals corresponding to 
[(Salen) $\left.\mathrm{Co}^{\mathrm{III}} \mathrm{Cl}+\mathrm{PO}+\mathrm{CO}\right]^{+}$(see Figure $\mathrm{S} 1$ in the Supporting Information), suggesting that the (Salen)cobalt-alkoxo complexes were completely converted to the targeted alkoxycarbonyl cobalt Salen complexes (3a and $\mathbf{3} \mathbf{b}$ ). This green powder was also analyzed by ${ }^{1} \mathrm{H}$ and ${ }^{13} \mathrm{C}$ NMR (see Figures S2 and S3). By comparison of these spectra with those of pure $3 \mathbf{a}$ that was obtained following the protocol described in literature (see Figures S4 and S5), ${ }^{11}$ the $\mathbf{3 a} / \mathbf{3} \mathbf{b}$ ratio could be determined as $77: 23$, indicative of the preferential attack on the sterically unhindered epoxide ring carbon atom during the ring opening reaction. The direct treatment of 1 with $\mathrm{PO}$ and $1 \mathrm{~atm}$ of $\mathrm{CO}$ also generated the alkoxycarbonyl cobalt Salen complexes, suggesting that $\mathrm{CO}$ does not hinder the PO ring opening on the cobalt Salen complex. The 3a/3b mixture initiated a well-controlled OMRP of methyl acrylate (MA) after an induction period of about $1 \mathrm{~h}$ under a light intensity of $10 \mathrm{~mW} \cdot \mathrm{cm}^{-2}$. MALDI-TOF-MS spectra of the resultant poly(methyl acrylate) (PMA) exhibited two series of peaks in accordance with $\left(\mathrm{Cl}+\mathrm{PO}+\mathrm{CO}+\mathrm{MA}_{n}+\mathrm{OH}\right) \mathrm{Na}^{+}$and $(\mathrm{Cl}+\mathrm{PO}+$ $\left.\mathrm{CO}+\mathrm{MA}_{n}+\mathrm{OH}\right) \mathrm{K}^{+}$, respetively (Figure S7). This suggests that the alkoxycarbonyl cobalt Salen complexes undergo Co-acyl bond homolysis and generate alkoxycarbonyl radicals able to initiate the polymerization, which is in full agreement with the work by $\mathrm{Fu}$ and Peng. ${ }^{11}$ Further experiments involving the epoxides/anhydrides ROCOP followed by the CO addition were performed to test whether each of the ROCOP active species could be effectively carbonylated (Scheme $3 C$ ). In a first experiment, the ROCOP of $\mathrm{PO}$ and phthalic anhydride (PA) catalyzed by 1 was conducted in the presence of a large $P O$ excess $([P O] /[P A] /[1]=1000 / 100 / 1)$, ensuring the generation of the [(Salen)Coll'-O-PPE] chain end (Scheme $3 \mathrm{C} 1$ ). CO was then added after a specific polymerization time. As revealed by NMR spectroscopy, the PA consumption stopped after the $\mathrm{CO}$ addition (see Figures S8 and S9). This suggests that CO quickly terminates the copolymerization reaction. The final product had a dark green color, consistent with the formation of a carbonyl cobalt Salen complex. The ${ }^{1} \mathrm{H}$ NMR and GPC analyses confirmed that the product is poly(propylene phthalate) (PPE) with complete alternation of $\mathrm{PO}$ and PA monomers and with a number average molecular weight $\left(M_{\mathrm{n}}\right)$ of $4.3 \mathrm{~kg} / \mathrm{mol}$ and dispersity of 1.10 (see Figures S10 and S11). The ESI-MS analysis showed two series of signals in accordance with [(Salen) $\mathrm{Co}^{\mathrm{III}} \mathrm{Cl}+\mathrm{PO}+\mathrm{CO}+(\mathrm{PO}+$ $\left.\mathrm{PA})_{n}\right] \mathrm{Na}^{+}$and $\left[(\right.$Salen $\left.) \mathrm{Co}^{\prime \prime \prime} \mathrm{Cl}+\mathrm{PO}+\mathrm{CO}+(\mathrm{PO}+\mathrm{PA})_{n}\right] \mathrm{K}^{+}$, respectively (see Figure S12), indicative of the full conversion of the alkyoxy active species [(Salen)Co'II-O-PPE] into (Salen)Co ${ }^{\text {III- }}$ $\mathrm{CO}_{2}$-PPE. Furthermore, an isotope labeling experiment using ${ }^{13} \mathrm{CO}$ was conducted and the resultant polymeric product was confirmed as (Salen)Co ${ }^{\text {III }}-\mathrm{C}^{13} \mathrm{O}_{2}$-PPE according to the ESI-MS analysis (Figure S14), which further elucidates the mechanistic aspects related to the $\mathrm{CO}$ insertion process. This material was able to photoinitiate the OMRP of MA (vide infra). The comparative ROCOP experiments with excess PA (Scheme 3C2), aiming at the selective formation of a carboxyl chain end [(Salen)Co $\left.\mathrm{Co}^{\text {III-O}} \mathrm{O}_{2} \mathrm{C}-\mathrm{PPE}\right]$ after full PO conversion, was executed in toluene $([P O] /[P A] /[1] /[$ toluene $]=20 / 100 / 1 / 200)$. As for the previous experiment, $\mathrm{CO}$ was added at the end of the polymerization, but a white product was obtained in this case (see Figures S15 and S16). The ESI-MS analysis of the product exhibited two series of signals, which could be assigned to $[\mathrm{Cl}+$ $\left.\mathrm{PO}+(\mathrm{PO}+\mathrm{PA})_{n}+\mathrm{H}\right] \mathrm{Na}^{+}$and $\left[\mathrm{Cl}+\mathrm{PO}+(\mathrm{PO}+\mathrm{PA})_{n}+\mathrm{H}^{+} \mathrm{K}^{+}\right.$ respectively (see Figure $\mathrm{S} 17$ ). Moreover, this material was not a suitable photoinitiator for the OMRP of MA. Therefore, we envision that $\mathrm{CO}$ can only insert into the $\mathrm{Co}-\mathrm{O}$ bond of (Salen)Co'll-O-PPE and not into that of (Salen)Co ${ }^{\text {III- }}-\mathrm{O}_{2}$ C-PPE. In this regard, we propose that (Salen) $\mathrm{Co}{ }^{\mathrm{II}}-\mathrm{O}_{2} \mathrm{C}-\mathrm{PPE}$ can stoichiometrically ring-open $\mathrm{PO}$ in the presence of $\mathrm{CO}$ to generate (Salen)Co'l'- $\mathrm{CO}_{2}-\mathrm{PPE}$, thus enabling the full conversion of the ROCOP active species into the carboalkoxo cobalt Salen complexes (Scheme 3C).

DFT Calculations.The remarkable and unprecedented experimental finding of a CO insertion into a Co"l'-alkoxide species to yield a Co'II-carboalkoxy species was further investigated by DFT calculations in order to confirm its feasibility and to assess which of the three envisaged mechanisms in Scheme $3 \mathrm{~A}$ would be preferred. Since two of the three mechanisms involve a charge separation (Scheme 3, A1 and A3), the calculations included a polarizable continuum model in propylene oxide, which was used in large excess, as solvent $(\varepsilon=16.0)$ and a correction for dispersion forces was also included. ${ }^{20}$ The calculations were carried out with the DFT approach at the full QM level, using slightly simplified ligands for the sake of computational efficiency. The tBu substituents on the Salen ligand were replaced with $\mathrm{Me}$ groups to yield the Salen* model and the polymer chain beyond the cobalt-bonded PO unit in the polymeric -O-PPE alkoxide ligand was replaced by an $\mathrm{H}$ atom to yield the $\mathrm{O}-\mathrm{CH}(\mathrm{Me}) \mathrm{CH}_{2} \mathrm{OH}$ alkoxide model. For other computational details, see the SI. The salient results are summarized in Figure 1. The ionic dissociation of the alkoxide to yield the $\left[\mathrm{Co}\left(\text { Salen }^{*}\right)\right]^{+} /-\mathrm{OCHMeCH} \mathrm{CH}_{2} \mathrm{OH}$ ion pair is energetically very costly, even in the dielectric solvent (56.8 $\mathrm{kcal} / \mathrm{mol}$ ). Before solvation correction, the corresponding $\Delta G_{298 \mathrm{k}, 1 \mathrm{M}}$ is $142.4 \mathrm{kcal} / \mathrm{mol}$. Therefore, this pathway appears unfeasible. On the other hand, $\mathrm{CO}$ addition to the $\left[\mathrm{Co}\left(\mathrm{Salen}^{*}\right)(\mathrm{CO})\left(\mathrm{OCHMeCH}{ }_{2} \mathrm{OH}\right)\right]$ intermediate is relative facile. Two isomers may be obtained, the most stable of which has a trans configuration $\left(\Delta G_{298 \mathrm{~K}, \mathrm{PO}, 1 \mathrm{M}}=-7.6 \mathrm{kcal} / \mathrm{mol}\right)$. This isomer does not have an appropriate ligand arrangement for the migratory insertion step of pathway $A 2$, but could lead to the ionic dissociation of pathway A3. This, however, is once again energetically too costly $\left(\Delta G_{298 \mathrm{~K}, \mathrm{PO}, 1 \mathrm{M}}=47.4 \mathrm{kcal} / \mathrm{mol}\right)$. The alternative $\left[\mathrm{Co}\left(\mathrm{Salen}^{*}\right)(\mathrm{CO})\left(\mathrm{OCHMeCH} \mathrm{CH}_{2} \mathrm{OH}\right)\right]$ isomer with a cis relative arrangement of the $\mathrm{CO}$ and alkoxide ligands is slightly endoergic but kinetically accessible $(1.4 \mathrm{kcal} / \mathrm{mol})$, with a slightly exoenergetic bond formation $(-4.2 \mathrm{kcal} / \mathrm{mol})$ and a mild stabilization by solvation $(-4.1 \mathrm{kcal} / \mathrm{mol})$. The subsequent $\mathrm{CO}$ insertion is very facile, with a barrier of only $4.8 \mathrm{kcal} / \mathrm{mol}$ from the carbonyl adduct or $3.4 \mathrm{kcal} / \mathrm{mol}$ from the separated reagents, and is very exothermic. Thus, the transformation of the alkoxide into the carboalkoxyl group by $\mathrm{CO}$ addition is predicted to be irreversible. Calculations were also carried out to assess the 


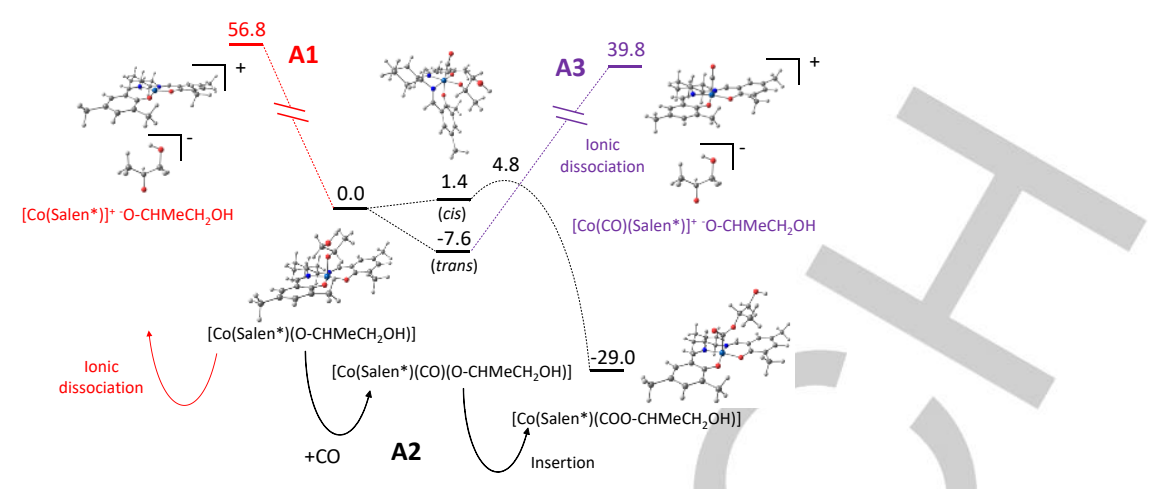

Figure 1. Free energy profile $\left(\Delta G_{298 k, 1 \mathrm{M}}\right)$ in $\mathrm{PO}(\varepsilon=16.0)$ for the reaction between $\left[\mathrm{Co}\left(\mathrm{Salen}^{*}\right)\left(\mathrm{OCHMeCH}_{2} \mathrm{OH}\right)\right]$ and $\mathrm{CO}$ to yield $\left[\mathrm{Co}\left(\mathrm{Salen}^{*}\right)\left(\mathrm{COOCHMeCH}_{2} \mathrm{OH}\right)\right]$.

homolytic bond strength of the Co'll-E $(\mathrm{E}=\mathrm{O}$ or $\mathrm{C})$ bond in the various complexes involved in this work. As a reference, the bond dissociation free energy (BDFE) of [(Salen*) $\mathrm{Co}^{\text {"II- }}$ $\left.\mathrm{CH}\left(\mathrm{CH}_{3}\right) \mathrm{CO}_{2} \mathrm{CH}_{3}\right]$ in the $\mathrm{PO}$ medium at $298 \mathrm{~K}$ was calculated as 19. $7 \mathrm{kcal} / \mathrm{mol}$. The Coll'-O bond in [(Salen $\left.{ }^{\star}\right) \mathrm{Co}^{\prime \prime \prime}-$ $\mathrm{OCH}\left(\mathrm{CH}_{3}\right) \mathrm{CH}_{2} \mathrm{OH}$ ] is homolytically stronger $(28.1 \mathrm{kcal} / \mathrm{mol})$, consistent with the observation that the [(Salen)Co $\left.{ }^{\prime \prime \prime}-O-P P E\right]$ does not initiate the OMRP of MA. Finally, the Coll-C bond in

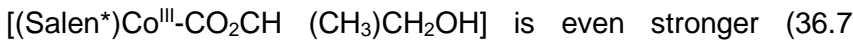
$\mathrm{kcal} / \mathrm{mol})$. This suggests that [(Salen) $\left.\mathrm{Co}^{\mathrm{III}}-\mathrm{CO}_{2}-\mathrm{PEE}\right]$ produced by $\mathrm{CO}$ insertion will not spontaneously initiate the radical polymerization of MA under thermal activation.

Light initiated OMRP of MA mediated by (Salen) $\mathrm{Co}^{\text {"II-CO }}{ }_{2}$-PPE. The (Salen) $\mathrm{Co}^{\text {III-}}-\mathrm{CO}_{2}$-PPE product obtained from the procedure of Scheme 3C2 $\left(M_{\mathrm{n}}=5.3 \mathrm{kDa}, \emptyset=1.15\right)$ was explored as the photoinitiator for the OMRP of MA under periodic light on-off process (Figure 2). Figure 2a reveals that visible light could give ON/OFF control over the living chain growth of PPE- $b$-PMA. During the whole procedure, the polymerization was wellcontrolled, as indicated by the kinetic study (Figures $2 \mathrm{~b}$ and $2 \mathrm{c}$ ) and by the excellent match between experimental and observed molar masses. The OMRP of MA was observed to proceed with linear first-order kinetics with an induction period and an apparent polymerization rate of $5.4 \times 10^{-2} \cdot \mathrm{h}^{-1}$, from which the radical concentration was estimated as $\sim 1.11 \times 10^{-9} \mathrm{M}$. The low concentration of propagating radicals largely minimized undesirable side reactions leading to dead polymers and ensured the living character. This was expected on the basis of the previous MA polymerization study with control by (Salen)Co III$\mathrm{CO}_{2}-\mathrm{Me} .{ }^{11}$ Moreover, the GPC curves of the polymeric products displayed monomodal and narrow distributions as well as a continuous molecular weight increase (Figure 2d), in agreement with the formation of PPE- $b$-PMA. In order to investigate the effect of light on the OMRP of MA after the induction period, comparative experiments have been conducted $(I)$ for $4 \mathrm{~h}$ under a light intensity of $10 \mathrm{~mW} \cdot \mathrm{cm}^{-2}$, (ii) for $1 \mathrm{~h}$ under a light intensity of $10 \mathrm{~mW} \cdot \mathrm{cm}^{-2}+3 \mathrm{~h}$ under a light intensity of $5 \mathrm{~mW} \cdot \mathrm{cm}^{-2}$, (iii) for $1 \mathrm{~h}$ under a light intensity of $10 \mathrm{~mW} \cdot \mathrm{cm}^{-2}+3 \mathrm{~h}$ in the dark and (iv) only for $1 \mathrm{~h}$ under a light intensity of $10 \mathrm{~mW} \cdot \mathrm{cm}^{-2}$. The conversions of MA were $28.8 \%, 17.6 \%, 14.3 \%$ and $5.4 \%$, respectively, suggesting that the polymerization does not require constant irradiation with light, but at the same time the polymerization rate scales with the light intensity (Figures S18-S21). It is notable that the induction periods under light density of $5 \mathrm{~mW} \cdot \mathrm{cm}^{-2}$ and 10 $\mathrm{mW} \cdot \mathrm{cm}^{-2}$ are around $2 \mathrm{~h}$ and $1 \mathrm{~h}$, respectively, indicating that stronger light density is favorable for shortening the induction periods of the OMRP mediated by the in-situ generated alkoxycarbonyl cobalt Salen complexes via CO insertion into Co$\mathrm{O}$ bonds.

CO-triggered switchable polymerization from ROCOP to OMRP. Encouraged by these results, several one-pot terpolymerizations of epoxides, anhydrides and acrylates were conducted in ampules at room temperature (Table 1). The reactions comprised three stages: 1) ROCOP of the epoxides/anhydrides mixture; 2) chain-end modification by addition of $\mathrm{CO}$; 3 ) visible light initiated OMRP of acrylates. The ampules were kept in the dark (wrapped by aluminum foil) during steps 1 and 2 . The reactions were monitored by ${ }^{1} \mathrm{H}$ NMR analysis of aliquots taken at regular intervals. At first, PO, PA and MA were used as the model substrates (Table 1, entries 1-5). Given that $\mathrm{CO}$ and visible light could provide temporal control over the ROCOP/OMRP switch and the OMRP process, respectively, it is possible to precisely manipulate the incorporation of monomers into the resulting polymer chains. Taking entry 1 as an example, ROCOP and OMRP occurred during the first stage and the third stage, respectively, as revealed by the ${ }^{1} \mathrm{H}$ NMR spectra (Figures S22-23). According to the NMR characterization of the isolated products, both PPE with a completely alternating PO/PA structure and PMA formed in the one-pot procedure. However, no signals corresponding to the junction units could be detected (see Figures S24-S26). Both the GPC curves of products of the first stage and the third stage exhibited monomodal and narrow distribution (Figure S27). Moreover, the theoretical molecular weights calculated from the monomer conversions were all in good agreement with the values obtained from the GPC curves. It is notable that polyester/polyacrylate ratio measured by NMR $(1: 2.26)$ agree well with that calculated from GPC analysis (1:2.29). To unambiguously verify the block structure, the 
polymers were analyzed by DOSY NMR spectroscopy (Table 1, entry 1). The characteristic signals of both PPE and PMA blocks shared the same diffusion coefficient, whereas a blend of the PPE/PMA constituents, which were expressly synthesized by PO/PA ROCOP and by MA OMRP with approximately the same chain length ratio as the diblock copolymer, displayed two diffusion coefficients (see Figures S28 and S29). Furthermore, the quantitative insertion of $\mathrm{CO}$ into $\mathrm{Co}-\mathrm{O}$ bonds also occurred when the $\mathrm{CO}$ insertion process was reduced from $12 \mathrm{~h}$ to $30 \mathrm{~min}$ (Table 1, entry 5). It is notable that, after the final OMRP stage,
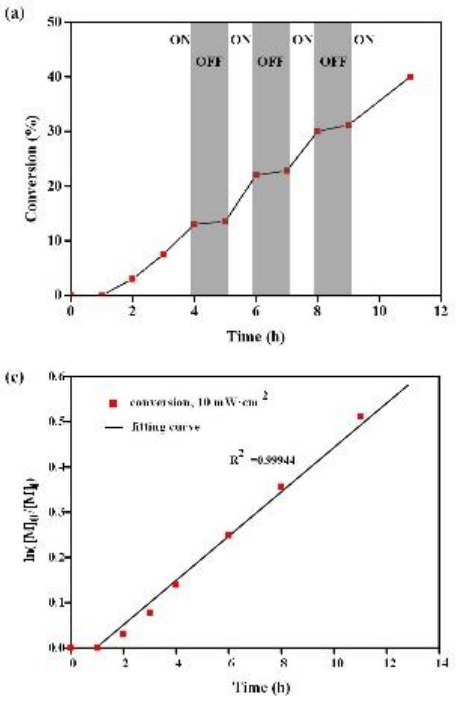

the PPE- $b$-PMA product has a (Salen)Co chain-end function linked via a Co-C bond, allowing postpolymerization modification via treatment with radical scavengers such as thiols or nitroxides. By direct addition of 2,2,6,6-tetramethylpiperidine-1-oxyl (TEMPO) into the reaction mixture after the third stage of the reaction (Table 1 , entry 2 ), we successfully synthesized PPE- $b$ PMA macromolecules end-capped with TEMPO (Scheme 4), as confirmed by ${ }^{1} \mathrm{H}$ NMR spectroscopy (see Figure S30), yielding an isolated polymer in the form of a white powder.

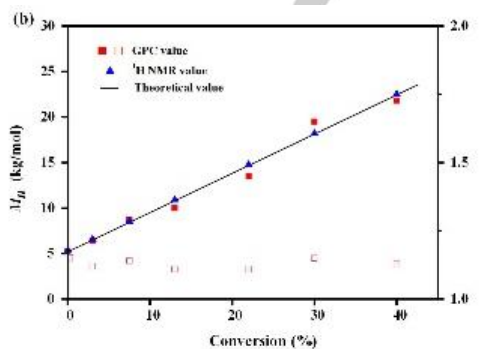

(d)

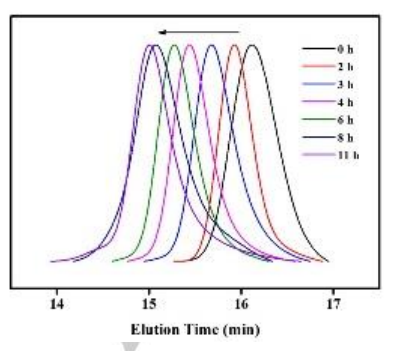

Figure 2. Visible light initiated OMRP of MA mediated by (Salen)Co ${ }^{\prime \prime \prime}-\mathrm{CO}_{2}-\mathrm{PPE}\left(M_{\mathrm{n}}=5.3 \mathrm{kDa}, \oplus=1.15\right)$ at room temperature; a household white LED lamp was used as the light source (the light intensity was $10 \mathrm{~mW} \cdot \mathrm{cm}^{-2}$ at the sample position). (a) Investigation of the "ON/OFF" switching regulated by light. (b) Evolution of number-average molecular weight and polydispersity $\left(M_{\mathrm{w}} / M_{\mathrm{n}}\right)$ with the MA conversion; the straight line represents the theoretical mass weight evolution. (c) Kinetic plot for the OMRP of MA. (d) Evolution of the GPC traces.

Table 1. One-pot synthesis of block copolymers via CO triggered switchable polymerization from the ROCOP of epoxides/anhydrides to the OMRP of acrylates. ${ }^{a}$

\begin{tabular}{|c|c|c|c|c|c|c|c|c|c|}
\hline \multirow[b]{2}{*}{ Entry } & \multirow[b]{2}{*}{ Monomer } & \multicolumn{2}{|c|}{ ROCOP } & \multicolumn{2}{|c|}{ OMRP } & \multirow[b]{2}{*}{$\begin{array}{c}\text { Polyester } \\
\text { /Polyacrylate }\end{array}$} & \multirow[b]{2}{*}{$\begin{array}{c}M_{\mathrm{n}, \text { theo }}{ }^{\mathrm{C}} \\
(\mathrm{kg} / \mathrm{mol})\end{array}$} & \multirow[b]{2}{*}{$\begin{array}{c}M_{n, \mathrm{GPC}^{d}} \\
(\mathrm{~kg} / \mathrm{mol})\end{array}$} & \multirow[b]{2}{*}{$\bigoplus^{d}$} \\
\hline & & Time $(h)$ & $\begin{array}{l}\text { Conv. }(\%)^{b} \\
\text { (anhydride) }\end{array}$ & Time (min) & $\begin{array}{c}\text { Conv. }(\%)^{b} \\
\text { (acrylate) }\end{array}$ & & & & \\
\hline $2^{e}$ & {$[\mathrm{PO}] /[\mathrm{PA}] /[\mathrm{MA}]$} & 60 & 40 & 10 & 1 & $1 / 0.10$ & 9.1 & 8.2 & 1.13 \\
\hline 3 & {$[\mathrm{PO}] /[\mathrm{PA}] /[\mathrm{MA}]$} & 72 & 46 & 50 & 35 & $1 / 8.73$ & 39.5 & 36.7 & 1.25 \\
\hline $5^{f}$ & {$[\mathrm{PO}] /[\mathrm{PA}] /[\mathrm{MA}]$} & 96 & 58 & 50 & 16 & $1 / 1$ & 25.8 & 24.6 & 1.13 \\
\hline 6 & {$[\mathrm{PO}] /[\mathrm{PA}] /[\mathrm{nBA}]$} & 48 & 31 & 20 & 4 & $1 / 2.20$ & 11.5 & 9.2 & 1.11 \\
\hline 7 & {$[\mathrm{EO}] /[\mathrm{PA}] /[\mathrm{MA}]$} & 24 & 73 & 60 & 9 & $1 / 1.26$ & 21.7 & 19.8 & 1.11 \\
\hline 8 & {$[\mathrm{EO}] /[\mathrm{CHA}] /[\mathrm{MA}]$} & 12 & 23 & 60 & 33 & $1 / 4.28$ & 33.0 & 30.4 & 1.16 \\
\hline 9 & {$[\mathrm{EO}] /[\mathrm{THPA}] /[\mathrm{MA}]$} & 25 & 70 & 50 & 18 & $1 / 0.75$ & 29.2 & 27.3 & 1.16 \\
\hline 11 & {$[\mathrm{PO}] /[\mathrm{NBA}] /[\mathrm{nBA}]$} & 60 & 29 & 25 & 2 & $1 / 0.30$ & 9.0 & 7.7 & 1.14 \\
\hline
\end{tabular}

aConditions: room temperature; [epoxide]/[anhydride]/[acrylate]/[Complex 1] = 1000/100/1000/1; CO insertion processes run for 12 h; light source for OMRP: household white LED lamp $\left(10 \mathrm{mWcm}^{-2}\right.$ at the sample position). ${ }^{b}$ Determined by ${ }^{1} \mathrm{H}$ NMR spectroscopy. ${ }^{c} M_{\mathrm{n}, \text { theo }}=\left[M_{\mathrm{w}}(\mathrm{epoxide})+M_{\mathrm{w}}(\right.$ anhydride $\left.)\right] \times 100 \times$ Conv.(anhydride) $+M_{\mathrm{w}}$ (acrylate) $\times 1000 \times$ Conv.(acrylate). ${ }^{d}$ Determined by GPC analysis in THF, calibrated against polystyrene standards. ${ }^{e}$ Terminated with TEMPO. 'The CO insertion process runs for $30 \mathrm{~min}$. 
The monomer scope was subsequently expanded using ethylene oxide (EO), cyclohexene anhydride ( $\mathrm{CHA}$ ), cis-5-norborneneendo-2,3-dicarboxylic anhydride (NBA), cis-1,2,3,6tetrahydrophthalic anhydride (THPA) and n-butyl acrylate (nBA) (Table 1, entries 6-10). In all cases, the targeted polyester- $b$ polyacrylates were successfully obtained with narrow distributions $(\Theta<1.17)$ (see Figures S32-S62).

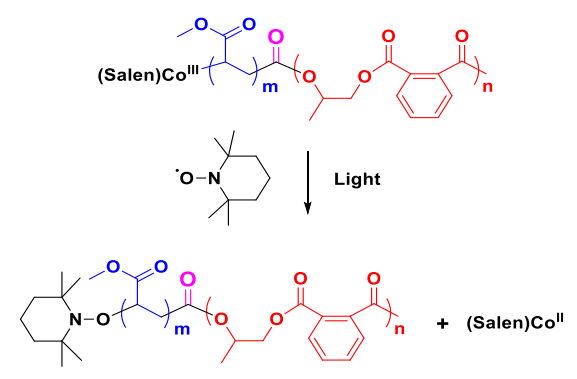

Scheme 4. Postpolymerization modification of (Salen)Co terminated diblock PPE- $b$-PMA via treatment with TEMPO.

\section{Conclusion}

In summary, the first example of a switch from the ring-opening copolymerization (ROCOP) of epoxides/anhydrides to a lightinitiated organometallic mediated controlled radical polymerization (OMRP) of vinyl monomers has been described, using a (Salen)Co system as a common catalyst/moderating agent and $\mathrm{CO}$ as a molecular trigger. Central to this protocol is the direct insertion of $\mathrm{CO}$ into the $\mathrm{Co}-\mathrm{O}$ bond of the ROCOP active

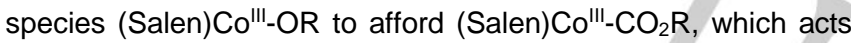
as successful OMRP photoinitiator for the OMRP of MA. Mechanistic aspects concerning the quantitative transformation of the $\mathrm{Co}-\mathrm{O}$ bond into a $\mathrm{Co}-\mathrm{CO}_{2}$ bond have been reasonably proposed, as confirmed by experimental results and supported by DFT calculations. This constitutes the first example of $\mathrm{CO}$ insertion into a metal-alkoxide bond for cobalt and for any metal in the oxidation state III. Regulated by both $\mathrm{CO}$ and light, ondemand monomer incorporation has been demonstrated for the one-pot terpolymerization of epoxides, anhydrides and acrylates, allowing the elaboration of polyester-b-polyacrylate diblock copolymers with precisely programmed sequence, relative block lengths and chain-end functionality.

\section{Experimental Section}

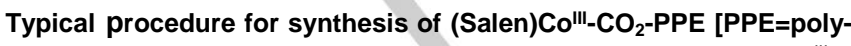
(propylene phthalate)]. In an argon filled glove box, (Salen) $\mathrm{Co}{ }^{\prime \prime \prime} \mathrm{Cl}$ complex (63.9 mg, $0.1 \mathrm{mmol}), \mathrm{PA}(1.48 \mathrm{~g}, 10 \mathrm{mmol})$ and PO (7.0 mL, 100 $\mathrm{mmol}$ ) were charged into a $25 \mathrm{~mL}$ ampoule, which was wrapped in aluminum foil and equipped with a magnetic stir bar. The ampoule was taken out of the glove box and allowed to stirred at $25^{\circ} \mathrm{C}$ for $24 \mathrm{~h}$ before it was degassed and pressurized with $1 \mathrm{~atm} \mathrm{CO}$. Then, the ampoule was allowed to stir at $25^{\circ} \mathrm{C}$ for $12 \mathrm{~h}$. A small aliquot of the polymerization mixture was taken out for ${ }^{1} \mathrm{H}$ NMR spectroscopy and the remained crude mixture was precipitated in cold $\mathrm{n}$-hexane.
Typical procedure for visible light initiated OMRP of MA mediated by (Salen)Co'll- $\mathrm{CO}_{2}$-PPE. In an argon filled glove box, (Salen) $\mathrm{Co}^{\prime \prime \prime}-\mathrm{CO}_{2}$-PPE $\left(M_{\mathrm{n}}=5.3 \mathrm{kDa}, \Xi=1.15\right)$, MA were charged into a $25 \mathrm{~mL}$ ampoule equipped with a magnetic stir bar, [(Salen)Co $\left.{ }^{\prime \prime \prime}-\mathrm{CO}_{2}-\mathrm{PPE}\right] /[\mathrm{MA}]=1 / 1000,[\mathrm{M}]_{0}=1.0 \mathrm{M}$ solvent: $\mathrm{CH}_{2} \mathrm{Cl}_{2}$. The ampoule was then taken out of the glove box and allowed to stirred at $25^{\circ} \mathrm{C}$ under irradiation of a household white LED lamp with light intensity of $10 \mathrm{~mW} \cdot \mathrm{cm}^{-2}$. A small aliquot of the polymerization mixture was taken out for ${ }^{1} \mathrm{H}$ NMR spectroscopy and the remained crude mixture was precipitated in cold $n$-hexane.

Typical procedure for $\mathrm{CO}$ triggered switchable polymerization from ROCOP to OMRP. In an argon filled glove box, (Salen) $\mathrm{Co}{ }^{\text {III }} \mathrm{Cl}$ complex (63.9 mg, $0.1 \mathrm{mmol}), \mathrm{PA}(1.48 \mathrm{~g}, 10 \mathrm{mmol}), \mathrm{MA}(9.0 \mathrm{~mL}, 100 \mathrm{mmol})$ and PO $(7.0 \mathrm{~mL}, 100 \mathrm{mmol})$ were charged into a $25 \mathrm{~mL}$ ampoule, which was wrapped in aluminum foil and equipped with a magnetic stir bar. The ampoule was then taken out of the glove box and allowed to stirred at 25 ${ }^{\circ} \mathrm{C}$. After the allotted reaction time, it was degassed and pressurized with $1 \mathrm{~atm} \mathrm{CO}$ and allowed to stir at $25^{\circ} \mathrm{C}$ for $12 \mathrm{~h}$. Next, the aluminum foil was uncovered and the ampule was degassed and pressurized with $1 \mathrm{~atm}$ argon and allowed to stir at ambient temperature under irradiation of a household white LED lamp with light intensity of $10 \mathrm{~mW} \cdot \mathrm{cm}^{-2}$. A small aliquot of the polymerization mixture was taken out for ${ }^{1} \mathrm{H}$ NMR spectroscopy and the remained crude mixture was precipitated in cold nhexane.

\section{Acknowledgements}

YW, YJZ and XPZ thank the Financial support from National Key R\&D Plan (No.2016YFB0302400), NSFC (No.21604027) of china, the Fundamental Research Funds for the Central Universities (HUST:2019JYCXJJ015) as well as the analytical and testing assistance from the Analysis and Testing Center of HUST. RP thanks the CNRS (Centre National de la Recherche Scientifique) for support and the CALMIP mesocenter of the University of Toulouse for the allocation of computational resources.

\section{Conflict of interest}

The authors declare no conflict of interest

Keywords: Ring-opening copolymerization - organometallic mediated radical polymerization $\cdot$ switch catalysis $\bullet$ block copolymer • polypropylene carbonate

\section{References}

(1) Bates, F. S.; Hillmyer, M. A.; Lodge, T. P.; Bates, C. M.; Delaney, K. T.; Fredrickson, G. H. Science 2012, 336, 434-440.

(2) a) Eisenreich, F.; Kathan, M.; Dallmann, A.; Ihrig, S. P.; Schwaar, T. Schmidt, B. M.; Hecht, S. Nat. Catal. 2018, 1, 516-522. b) Chen, C. Nat. Rev. Chem. 2018, 2, 6-14. c) Teator, A. J.; Lastovickova, D. N.; Bielawski, C. W. Chem. Rev. 2016, 116, 1969-1992. d) Zhao, Y. J.; Wang, Y.; Zhou, X. P.; Xue, Z. G.; Wang, X. H.; Xie, X. L.; Poli, R. Angew. Chem. Int. Ed. 2019, 58, $14311-$ 14318; Angew. Chem 2019, 131, 14449-14456. e) Zhu, S. S., Zhao, Y. J., Ni, M. L., Xu, J., Zhou, X. P., Liao, Y. G., Wang, Y., Xie, X. L. Macro. Lett. 2020, 9, 204-209. f) Zhu, S. S., Wang, Y., Ding, W. Z., Zhou, X. P., Liao, Y. G., Xie, X. L. Polym. Chem. 2020, 10.1039/c9py01508f.

(3) a) Wang, X.; Thevenon, A.; Brosmer, J. L.; Yu, I.; Khan, S. I.; Mehrkhodavandi, P.; Diaconescu, P. L. J. Am. Chem. Soc. 2014, 136, 1126411267. b) Broderick, E. M.; Guo, N.; Vogel, C. S.; Xu, C.; Sutter, J. R.; Miller, J. 
T.; Meyer, K.; Mehrkhodavandi, P.; Diaconescu, P. L. J. Am. Chem. Soc. 2011, 133, 9278-9281. c) Wei, J.; Diaconescu, P. L. Accounts Chem. Res. 2019, 52, 415-424. d) Chen, C. ACS Catal. 2018, 8, 5506-5514.

(4) a) Qi, M.; Dong, Q.; Wang, D.; Byers, J. A. J. Am. Chem. Soc. 2018, 140, 5686-5690. b) Biernesser, A. B.; Delle Chiaie, K. R.; Curley, J. B.; Byers, J. A Angew. Chem. Int. Ed. 2016, 55, 5251-5254; Angew. Chem. 2016, 128, 53375340. c) Anderson, W. C.; Rhinehart, J. L.; Tennyson, A. G.; Long, B. K. J. Am. Chem. Soc. 2016, 138, 774-777.

(5) a) Longo, J. M.; Sanford, M. J.; Coates, G. W. Chem. Rev. 2016, 116, 15167-15197. b) Fieser, M. E.; Sanford, M. J.; Mitchell, L. A.; Dunbar, C. R. Mandal, M.; Van Zee, N. J.; Urness, D. M.; Cramer, C. J.; Coates, G. W.; Tolman, W. B. J. Am. Chem. Soc. 2017, 139, 15222-15231.

(6) a) Van Zee, N. J.; Coates, G. W. Angew. Chem. Int. Ed. 2015, 54, 2665 2668; Angew. Chem. 2015, 127, 2703-2706. b) Chen, Y.; Wilson, J. A.; Petersen S. R.; Luong, D.; Sallam, S.; Mao, J.; Wesdemiotis, C.; Becker, M. L. Angew. Chem. Int. Ed. 2018, 57, 12759-12764; Angew. Chem. 2018, 130, 12941-12946. (7) DiCiccio, A. M.; Longo, J. M.; Rodríguez-Calero, G. G.; Coates, G. W. J. Am. Chem. Soc. 2016, 138, 7107-7113.

(8) a) Abeles, R. H.; Dolphin, D. Accounts Chem. Res. 1976, 9, 114-120. b) Halpern, J. Science 1985, 227, 869.

(9) Demarteau, J.; Debuigne, A.; Detrembleur, C. Chem. Rev. 2019, 119, 6906-6955.

(10) a) Debuigne, A.; Poli, R.; Jérôme, C.; Jérôme, R.; Detrembleur, C. Prog. Polym. Sci. 2009, 34, 211-239. b) Banerjee, S.; Ladmiral, V.; Debuigne, A. Detrembleur, C.; Poli, R.; Améduri, B. Angew. Chem. Int. Ed. 2018, 57, 2934 2937; Angew. Chem. 2018, 130, 2984-2987. c) Debuigne, A.; Caille, J.-R.; Jérôme, R. Angew. Chem. Int. Ed. 2005, 44, 1101-1104; Angew. Chem. 2005, 117, 1125-1128. d) Poli, R. Angew. Chem. Int. Ed. 2006, 45, 5058-5070; Angew. Chem. 2006, 118, 5180-5192. e) Poli, R. Polymer Science: A Comprehensive Reference, Vol. 3, Elsevier BV, Amsterdam 2012, 351-357.

(11) Zhao, Y.; Yu, M.; Zhang, S.; Wu, Z.; Liu, Y.; Peng, C. H.; Fu, X. Chem Sci. 2015, 6, 2979-2988.

(12) a) Li, Y.; Zhang, Y. Y.; Hu, L. F.; Zhang, X. H.; Du, B. Y.; Xu, J. T. Prog. Polym. Sci. 2018, 82, 120-157. b) Wang, Y.; Zhao, Y. J.; Ye, Y. S.; Peng, H. Y.; Zhou, X. P.; Xie, X. L.; Wang, X. H.; Wang, F. S.; Angew. Chem. Int. Ed. 2018, 57, 3593-3597; Angew. Chem. 2018, 130, 3655- 3659. c) Darensbourg, D.J., Green Chem. 2019, 21, 2214-2223. d) Zhou, H. J.; Yang, G. W.; Zhang, Y. Y.; Xu, Z. K.; Wu, G. P. ACS Nano 2018, 12, 11471-11480.

(13) a) Peng, J. B.; Wu, F. P.; Wu, X. F. Chem. Rev. 2019, 119, 2090-2127. b) Drance, M. J.; Sears, J. D.; Mrse, A. M.; Moore, C. E.; Rheingold, A. L.; Neidig, M. L.; Figueroa, J. S. Science 2019, 363, 1203-1205. c) Wu, X. F.; Fang, X.; Wu, L.; Jackstell, R.; Neumann, H.; Beller, M. Accounts Chem.Res. 2014, 47, 1041 1053.

(14) a) Bennett, M. A.; Yoshida, T. J. Am. Chem. Soc. 1978, 100, 1750-1759. b) Rees, W. M.; Churchill, M. R.; Fettinger, J. C.; Atwood, J. D. Organometallics 1985, 4, 2179-2185. c) Kim, Y. J.; Osakada, K.; Takenaka, A.; Yamamoto, A. J. Am. Chem. Soc. 1990, 112, 1096-1104. d) Dockter, D. W.; Fanwick, P. E. Kubiak, C. P. J. Am. Chem. Soc. 1996, 118, 4846-4852. e) Kapteijn, G. M.; Dervisi, A.; Verhoef, M. J.; Frederik, M. A.; van den Broek, H.; Grove, D. M.; van Koten, G. J. Organomet. Chem. 1996, 517, 123-131.

(15) a) Schmidt, E.; Zhang, H.; Chang, C. K.; Babcock, G. T.; Oertling, W. A. J. Am. Chem. Soc. 1996, 118, 2954-2961. b) Kadish, X. H. M. a. K. M. Inorg. Chem. 1989, 28, 3743-3747.

(16) Willner, H.; Aubke, F. Angew. Chem. Int. Ed. 1997, 36, 2402-2425; Angew. Chem. 1997, 109, 2506.

(17) a) Cohen, C. T.; Chu, T.; Coates, G. W. J. Am. Chem. Soc. 2005, 127, 10869-10878. b) Ren, W. M.; Liu, Z. W.; Wen, Y. Q.; Zhang, R.; Lu, X. B. J. Am. Chem. Soc. 2009, 131, 11509-11518.

(18) a) Macgregor, S. A.; Neave, G. W. Organometallics 2003, 22, 4547-4556. b) Macgregor, S. A.; Neave, G. W. Organometallics 2004, 23, 891-899. c) Bi, S.; Zhao, J.; Fan, W. E. I.; Li, P. J. Theor. Comput. Chem. 2012, 11, 1-17.

(19) Robert, C.; Schmid, T. E.; Richard, V.; Haquette, P.; Raman, S. K.; Rager, M.-N.; Gauvin, R. M.; Morin, Y.; Trivelli, X.; Guérineau, V.; del Rosal, I.; Maron, L.; Thomas, C. M. J. Am. Chem. Soc. 2017, 139, 6217-6225.

(20) Smyth, C. P. Dielectric Behavior and Structure, Mc. Graw-Hill 1955, 79.

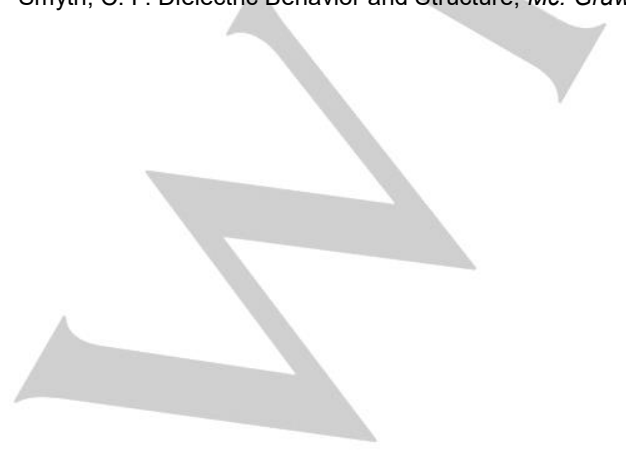


Entry for the Table of Contents (Please choose one layout)

\section{RESEARCH ARTICLE}

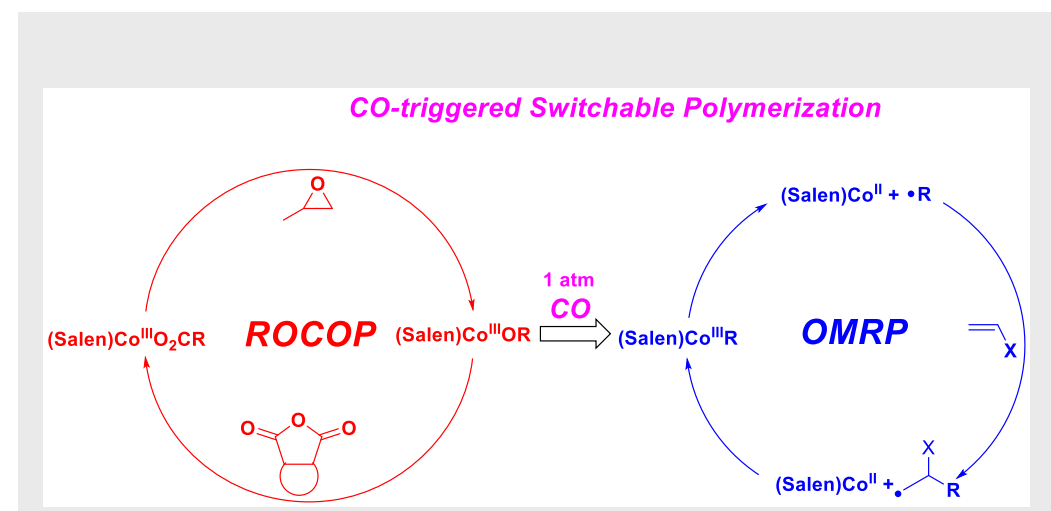

Yong Wang, ${ }^{*,}$ Yajun Zhao, ${ }^{+}$Shuaishuai Zhu, ${ }^{+}$Xingping Zhou, ${ }^{*}+$ Jing $X u, \neq$ Xiaolin $\mathrm{Xie}^{\dagger}$ and Rinaldo Poli,\&

Page No. - Page No.

Switchable Polymerization Triggered by Fast and Quantitative Insertion of Carbon Monoxide into Cobalt-Oxygen Bonds 